ORIGINAL ARTICLE

\title{
The Effect of Antenatal Corticosteroid Therapy to Respiratory Distress Syndrome Event on Preterm Infants in Surabaya
}

\author{
Devy Putri Zennita ${ }^{1}$, Martono Tri Utomo ${ }^{1}$, Ernawati Darmawan ${ }^{1 *}$ \\ ${ }^{1}$ Department of Obstetrics and Gynecology, Faculty of Medicine, Universitas Airlangga
}

\section{A R T I C L E I N F O}

Article history:

Received 30 April 2018

Received in revised 17 May 2018

Accepted 30 May 2018

Keywords:

Antenatal Corticosteroid Therapy

Respiratory Distress Syndrome

Prematurity.

*) Corresponding author:

ernawati_spog@gmail.com

\begin{abstract}
A B S T R A C T
Introductions: One of the most common cause of morbidity and mortality in preterm infants is respiratory distress syndrome (RDS). Several studies have shown that a single dose administration of antenatal corticosteroid therapy in women who are at high risk for preterm delivery was associated with decreased incidence of RDS. The study aims to determine the effect of antenatal corticosteroid therapy on the incidence of RDS in prematurity in the Department of Child Health Hospital Dr. Soetomo.

Methods: Analytic observational case-control design study was used for this research. Samples were taken from the medical records of RDS patients in preterm infants and nonRDS with 36 samples in each group.

Results: Antenatal corticosteroid therapy has effect in RDS incidence $(p=0.016)$. While the results of the odds ratio was 0.298 (with $95 \%$ CI 0.110 to 0.810 ), it means that preterm infants with antenatal corticosteroid therapy has 0.298 times lower risk than those who were not given antenatal corticosteroid therapy.

Conclusion: Antenatal corticosteroid therapy might be a protective factor that can reduce the incidence of RDS in prematurity.
\end{abstract}

\section{Introduction}

One of the leading causes of preterm infant mortality and mortality is Respiratory Distress Syndrome (RDS). The risk will continue to increase at birth less than 32 weeks. ${ }^{1}$ Administering a single dose of antenatal corticosteroid therapy in women at high risk for preterm delivery is associated with decreased incidence of RDS events, neonatal death and intra ventricular hemorrhagic (IVH) deaths. Corticosteroid antenatal administration may increase outcomes in infants born at 24 to 34 weeks' gestation and would be more beneficial if the delivery occurs at least within 24 hours after the first dose and less than seven days after the last dose of administration. $^{2}$

On previous research, Cochrane meta-analysis showed a statistically significant decrease in RDS in preterm infants born before 34 weeks of gestation (OR $0.36,95 \%$ CI $0.27-0.48)^{3}$. Similar findings were also found for premature births of less than 28 weeks, although the total number at this gestational age was small (OR 0.64, 95\% CI 0.16-2.50). ${ }^{4}$ Department Dr. Soetomo General Hospital Surabaya, Indonesia.

This study was conducted to find out how much effect of antenatal corticosteroid therapy on the occurrence of RDS in prematurity in Child Health

Biomolecular and Health Science Journal 


\section{Methods}

Observational Analytic Research with case control design was used for this research. Samples were taken from the medical records of RDS patients in preterm infants and non-RDS with 36 samples in each group. The data gathered from medical record then processed and analyzed descriptively. For nominal scale data, cross tabulation percentage was used while chi-square test and Odds ratio were used to define level of relationship significance.

\section{Results}

The result from cross tabulation of antenatal corticosteroid therapy in RDS incidence of preterm infants showed that the percentage of RDS patients who had history of antenatal corticosteroid therapy were $12.5 \%$ lower than those with no history of the therapy. Whereas in non-RDS patients, who had a history of antenatal corticosteroid therapy of $26 \%$ did not have much different from those who did not have a history of the therapy (Table 1).

Table 1. Distribution of Antenatal Corticosteroid Therapy

\begin{tabular}{|c|c|c|c|c|}
\hline \multirow{2}{*}{\multicolumn{2}{|c|}{$\begin{array}{c}\text { RDS in } \\
\text { Premature } \\
\text { Antenatal }\end{array}$}} & \multicolumn{2}{|c|}{$\begin{array}{c}\text { Antenatal } \\
\text { Corticosteroid } \\
\text { Therapy }\end{array}$} & \multirow{3}{*}{$\begin{array}{c}\text { Total } \\
36\end{array}$} \\
\hline & & \multirow{2}{*}{$\begin{array}{c}\text { Yes } \\
9\end{array}$} & \multirow{2}{*}{$\begin{array}{c}\text { No } \\
27\end{array}$} & \\
\hline Yes & $\mathrm{N}$ & & & \\
\hline & RDS & $12,5 \%$ & $37,5 \%$ & $50 \%$ \\
\hline \multirow[t]{2}{*}{ No } & $\mathrm{N}$ & 19 & 17 & 36 \\
\hline & RDS & $26 \%$ & $24 \%$ & $50 \%$ \\
\hline \multirow[t]{2}{*}{ Total } & $\%$ RDS & 28 & 44 & 72 \\
\hline & & $38.5 \%$ & $61.5 \%$ & $100 \%$ \\
\hline
\end{tabular}

The Chi-square analysis revealed $\mathrm{p}=0.016$. This means that $p$ is less than the significance level $(\alpha)$ of 0.05 , so it can be said that there is an influence between giving antenatal corticosteroid therapy to RDS occurrence in prematurity.

While the result of Odds Ratio analysis showed a value of 0.298 (with $95 \%$ Confidence Interval 0.110 0.810 or below value 1 ) which means that preterm infants with antenatal corticosteroid therapy have a risk of RDS 0.298 times lower than with preterm infants without antenatal corticosteroid therapy. It can be concluded that giving antenatal corticosteroid therapy did not provide a direct relationship to the incidence of Respiratory Distress Syndrome in preterm infants, but is a protective factor that can reduce the occurrence of RDS in prematurity. (Table 2)
Tabel 2 : Risk Estimate of RSD

\begin{tabular}{lccc}
\hline & \multirow{2}{*}{ Value } & \multicolumn{2}{c}{$\begin{array}{c}\text { 95\% Confidence } \\
\text { Interval }\end{array}$} \\
\cline { 3 - 4 } & & Lower & Upper \\
$\begin{array}{l}\text { Odds Ratio of } \\
\text { Antenatal } \\
\text { Corticosteroid Therapy } \\
\text { Antenatal }\end{array}$ & 0.298 & 0.110 & 0.810 \\
\hline
\end{tabular}

\section{Discussion}

The problem studied in this research is whether giving antenatal corticosteroid therapy has an effect on decreasing incidence rate of Respiratory Distress Syndrome (RDS) in preterm infants. In this study, two preterm infants group were studied, they were preterm infants with RDS who were given antenatal corticosteroid therapy and not and preterm infants who were not RDS patients (healthy preterm infants) who were given corticosteroid therapy and not.

The results of descriptive analysis showed that the incidence of preterm infant who suffered RDS and received antenatal corticosteroid therapy for 9 times $(12.5 \%)$ had a lower percentage compared with those who did not receive antenatal corticosteroid therapy. (Table 1) While the preterm infants who were not RDS patients did not differ significantly between those who received antenatal corticosteroid therapy and those who did not. The statistical analysis was done by Chi-square test and Odds Ratio (OR). Chi-square analysis results showed $\mathrm{P}=0.016$ that means giving antenatal corticosteroid therapy have influence on RDS incidence in prematurity. The result of value of odds ratio and Confidence Interval (CI) showed result OR $=0298$ (with $95 \%$ Confidence Interval $0.110-0.810)$. The result of OR $<1$ and $95 \%$ CI did not include number 1 means that antenatal corticosteroid therapy was a protective factor that reduced the incidence of RDS in prematurity. It can be argued that preterm infants without antenatal corticosteroid therapy have a 3 times risk of RDS infection compared to preterm infants with antenatal corticosteroid therapy.

The previous research also support the result above. Cochrane meta-analysis results in a randomized trial of 18 pregnant women showed that corticosteroid therapy may reduce the incidence of RDS, neonatal death and intraventricular hemorrhagic (IVH). The review showed a statistically significant decrease in the incidence of RDS in preterm infants born before 34 weeks of gestation, which showed OR 0.36 with $95 \%$ CI 0.27 $0.48 .{ }^{3}$

In addition, similar findings were also found for preterm births of less than 28 weeks. Although the total number at this gestational age is small, ie OR 0.64 and $95 \%$ CI $0.16-2.50$. An analysis of the number needed for 
treatment indicates that after 34 weeks, 94 women will need to be treated to prevent one RDS case, while before 31 weeks an RDS case is prevented for every five women treated. ${ }^{4}$

In animal studies, corticosteroids have been shown to help the lungs to mature. Corticosteroids are given to women at the onset of labor in order to help the infants's lungs mature and reduce the number of babies who die or suffer from respiratory problems at birth. Of the twentyone studies included, treatment with antenatal corticosteroids did not increase the risk of maternal death, chorioamnionitis or septic sepsis. Treatment with antenatal corticosteroids was associated with overall reduction in neonatal mortality (relative risk (RR) 0.69 , 95\% confidence interval (CI) 0,58-0,81, 18 studies, 3956 infants), RDS (RR 0.66 , 95\% CI 0.59-0.73, 21 studies, 4038 infants), cerebroventricular hemorrhage (RR 0.54, 95\% CI $0.43-0.69,13$ studies, 2,872 infants), enterocolitis necrosis (RR 0 , 46, 95\% CI 0.29-0.74, eight studies, 1675 infants), respiratory support, intensive care admissions (RR 0.80, 95\% CI 0.65-0.99, two studies, 277 infants) and systemic infections within the first 48 hours of life (RR $0.56,95 \%$ CI $0.38-0.85$, five studies, 1319 infants). The use of antenatal corticosteroids was effective in women with premature rupture of membranes and pregnancy related hypertensive syndromes. In addition, the outcome of this treatment in infants did not result in death and did not cause many common neurological problems and serious stomach, such as cerebroventricular hemorrhage and necrosis of enterocolitis, which affects infants born very early. In addition, there was no evidence of negative effects of corticosteroids in the mother and infants longterm goals in both. ${ }^{5-8}$

Liggins and Howie conducted a randomized study of $12 \mathrm{mg}$ intra-muscular betamethasone, 2 times within 24 hours, resulting in a significant reduction in the incidence of Respiratory Distress Syndrome (RDS) and a decrease in perinatal mortality born before 34 weeks. The treatment of betamethasone antenatal reduced the incidence of RDS $\pm 30 \%$ from $15.6 \%$ to $10 \%(\mathrm{P}=0.02)$ to 853 infants. There was a $60 \%$ reduction, from $23.7 \%$ to $8.8 \%(p=0.001)$, in subgroups giving birth over 24 hours, but less than 7 days after treatment. In the United States, in a multicenter randomized trial using dexamethasone, the incidence of RDS was reduced from $16.1 \%$ to $10.1 \%$ in the fetus given antenatal corticosteroid therapy. ${ }^{9,10}$

\section{Conclusion}

Based on the results of data analysis above, it can be concluded that the provision of antenatal corticosteroid therapy is a protective factor that can reduce the incidence of RDS in prematurity.

\section{Conflict of Interest}

The author stated there is no conflict of interest

\section{References}

1. Lemons JA, Bauer CR, Oh W, et al. Very low-birth weight infant (VLBW) outcomes of the NICHD neonatal research network. Pediatrics. 2001; 107: 1-8.

2. Smith JF. Prematurity. 2015.

3. Crowley P. Prophylactic corticosteroids for preterm birth. Cochrane Database Syst Rev 2002.

4. Goldenberg RL and McClure EM. Appropriate use of antenatal corticosteroid prophylaxis. Obstetrics and gynecology. 2015; 125: 285-7.

5. Roberts D, Brown J, Medley N and Dalziel SR. Antenatal corticosteroids for accelerating fetal lung maturation for women at risk of preterm birth. The Cochrane database of systematic reviews. 2017; 3: CD004454.

6. Roberts D. Antenatal corticosteroids in late preterm infants. Bmj. 2011; 342: d1614.

7. Utama DP and Crowther CA. Transplacental versus direct fetal corticosteroid treatment for accelerating fetal lung maturation where there is a risk of preterm birth. The Cochrane database of systematic reviews. 2011: CD008981.

8. Roberts D and Dalziel S. Antenatal corticosteroids for accelerating fetal lung maturation for women at risk of preterm birth. The Cochrane database of systematic reviews. 2006: CD004454.

9. Mercer BM. Assessment and Induction of Fetal Pulmonary Maturity; In Maternal-Fetal Medicine Principles and Practice. London: WB Saunders Company, Appleton \& lange, 2004.

10. Brownfoot FC, Gagliardi DI, Bain E, Middleton P and Crowther CA. Different corticosteroids and regimens for accelerating fetal lung maturation for women at risk of preterm birth. The Cochrane database of systematic reviews. 2013: CD006764. 